\title{
Causes, Effects and Issues of Homeless People
}

\section{Osama Alowaimer}

Northern Border University, Arar, Saudi Arabia

*Corresponding author: Dr. Osama Alowaimer, Teaching Assistant, Northern Border University, Arar, Saudi Arabia, Tel: 5407606353; E-mail: alowaio@hotmail.com Rec Date: August 04, 2017; Acc Date: September 6, 2018; Pub Date: September 14, 2018

Copyright: (C) 2018, Alowaimer O. This is an open-access article distributed under the terms of the Creative Commons Attribution License, which permits unrestricted use, distribution, and reproduction in any medium, provided the original author and source are credited.

\begin{abstract}
This article highlights homelessness as a social problem that exists in many societies and countries around the world. This phenomenon has become one of the biggest social problems facing the world in the twenty-first century. This encouraged the writer to investigate this phenomenon in his article. The article addresses some of the causes that lead to homelessness from the writer's point of view, the consequences of it, and the problems of homeless people. The writer mentions two main reasons for homelessness: lack of learning among homeless people and the use of drugs and alcohol. Whilst the writer states that the disease in homeless people is considered the most important effect of homelessness. As for the problems suffered by homeless persons, the writer determines the three most prominent which are poverty, hunger and loneliness.
\end{abstract}

Keywords: Homeless; Poor education; Poor people

\section{Introduction}

Life has a lot of good and bad affairs. However, people always look for the better. Therefore, they like just the nice affairs that help them to develop and ensure them a gracious life. On the other hand, there are bad affairs which make people unhappy when they see them or even just when they remember them, so they will feel uncomfortable. As a result, life will be more difficult for them. One of those affairs is homelessness. Homelessness exists in all countries and most communities in the world. Therefore, it is known that homelessness is the biggest social problem which the whole world faces in the twentyfirst century. That means that homelessness is an international issue that exists in a lot of societies and every locality people live in and some people in the world suffer from instability due to homelessness. Natural, homelessness is not a fine phenomenon because unfortunately it is a proof that there is a defect in the societies that have it. Apparently, homelessness affects personal life for homeless people themselves and others [1-4]. Therefore, it is very important to find a solution for this matter. To reach to a solution for any issue or problem, it needs a comprehensive study on it in all aspects, so as we get complete information about it. For example, we have to know, the causes which tend to it, the effects which consequent that issue, the issues which people suffer from them and the people themselves who suffer from it. Then, we will be able to choose the right solution for that phenomenon or issue. This applies to homeless people who we see every day. There are many causes and effects for homelessness. Also, homeless people have their own issues [5].

\section{Literature Review}

\section{The causes of homeless people}

Education is the most important requirement for everybody to get a fit job ensuring a dignified life. Otherwise, the existence will be complicated for him or her. Without education, the homeless people, especially children, will not have the opportunity to acquire important life skills [6]. Researches show that nearly to three-quarters of homeless youth give up going to school [7]. However, one of the main reasons of homelessness is lack of education or training for homeless people themselves. Homeless people face trammels which make them not attend schools or attend them intermittently. Homeless people are very poor, so they cannot afford the costs for their studies. They just look for the life even that they barely find food for themselves. Also, transportation is one of the barriers. Homeless families live in place away from the schools and they are unstable in specific shelters. This is because; searching for a safer and cheaper shelter is easier not in the city center. For example, the rent prices of accommodation in the farms are cheaper than the other parts of the city, so homeless people have to live there away from schools. In addition, the tuition in universities is of education or training barriers for many people and homeless people precisely. According to Desjardins [8], surveying about barriers to training in 2008 , there were $38 \%$ approximately of Canadians saying that training is too expensive, and they could not afford the cost. This percentage is high for people who are not homeless. So, absolutely, percentage of homeless people is higher, because they are poorer that the others. Also, this statistic is in Canada which is of the richest countries that means that percentage is higher in other society. In addition, the bad health for homeless people hinders them to go to schools. There are some of them who cannot walk on their feet, so they face a difficulty to go to their schools. Some of them are blind and alone that means it is impossible that they go to take classes by themselves. As everyone knows that encouragement is extremely crucial for everyone. Homeless people are losing encouragement to learn or at least develop themselves. Most of them live alone, so they do not have friends or anybody who encourages them. Consequently, they have the same feeling when they are studying or training or not. This means that they are unexcited to do anything even if it is tremendously paramount for them [9].

Of the other causes for homelessness is addiction, where the vast majority of homeless people use drugs and alcohol. Studies have found repeatedly that drug use is more prevalent among homeless people than others [10-14]. Rouse indicates in statistics conducted in Boston city that 91 percent of homeless people use alcohol, and 88 percent of them use different kinds of drugs [5]. This means that 9 percent only of homeless people use neither drugs nor alcohol, 2 percent of them use 
Page 2 of 4

either drugs or alcohol, and 88 percent of them use both drugs and alcohol. These percentages are high extremely. So, we conclude from previous statistic that there is a close relationship between using drugs or alcohol and homelessness. Among the most vulnerable and underprivileged groups in society are the homeless people who suffering from drugs, alcohol and mental disorders [15,16]. Naturally, there are reasons which made homeless people fell in this scourge which is indication. One of these motives is that they live in a bad psychological condition. Homeless people face poverty and hunger even that some of them do not have food. Therefore, they look for anything that makes them forget about their living situation which they suffer from. So, they suppose that drinking helps them to be glad and forget about their responsibilities towards themselves even if that is for a short period of time. In addition, it is easy for people who use drugs, alcohol or both to be homeless. This means addiction leads to homelessness in many times, where those abusers are ready to give up everything for the sake of getting drugs. For example, it is possible for addicted people to sale their houses, cars or anything which has a value for them to get money and buy drugs. This is because they need to take drugs by any way. As a result, homelessness may tend to addiction and addiction could tend to homelessness. As you know that addiction make addicted people unconscious to what is happening around them [17]. Subsequently, no one with a vacant job with accept them to work as long as they are addicted.

\section{The effects of homeless people}

However, there are many effects of homelessness. The diseases are of main for these effects of homeless people. Most of them have health problems. Some of diseases which they have are intractable or permanent such as cancer. In addition, they are vulnerable to dangerous diseases such as hepatitis and sexually transmitted infections [11]. Also, some of them are non-chronic. They suffer from diseases because of several reasons. One of these reasons is that homeless have difficulty accessing hospitals and health services (Hospital discharge of homeless people, 2012). Other reason is that they do not care about their personal hygiene. Where that, some of them are not taking a shower for a long period of time, maybe it reaches to consecutive three months. But, what about the reasons which made them do not bathe? There are many reasons; one of them is that they do not have houses that mean there is no place to take a shower for them. In addition, lack of awareness is one of core reasons. Where that there is no one tells them that ablution is very significant for their health. So, most of them do not have knowledge about the importance ablution for their health. This is because the majority of them do not have families and friends which mean they do not have anyone help to know the health ailments which maybe happened because of lack of ablution. Also, most of governments in the world do not contact with them and show them the risk of not washing. In addition, homeless youth suffer from psychological symptoms such as depression, anxiety and behavioral disorders at high rates [18-20].

One of them is violence. Violence is most of dangerous crime for all people, because often, it leads to death. There are many people in the world who suffer from violence and a lot of people classify the homeless as sources of violence in the societies. Many homeless people commit crimes such as theft, murder and kidnapping. If we look at the crimes that happened, we find that most of these are committed by homeless people. Last year's victims, a man called Mark Lufkin, 39, died in April last year after he was attacked at a homeless shelter in Concord. Also, there are a lot of victims due to homeless people. They are influential because of several reasons. One of these reasons is that some homeless people were influenced in the past when they were children from their families if they had ones or from any other people. As we know influence generates more influence. Therefore, they commit crimes, as a reaction for the action which happened for them in the past. In addition, the majority of homeless people do not have families and they lost anything in the life, so they feel that their life is empty. Therefore, they do not care about anything they do that means it is possible for them to kill or steal to the extent that they may commit suicide. Also, some people look to homeless people offensive look. Some of them look at homeless contempt look and disrespect them. For example, when a homeless person stays around a street and says hello to someone walks around him or her, the other person ignores him or her deliberately. This makes a kind of hostility toward the other person; so maybe, it develops to reach the valiance. This makes homeless feel there is more animus toward homeless people from some people. This makes homeless have a cruel reaction toward the societies [21]. In addition, diseases are of main effects for homeless people. Most of them have health problems. Some of diseases which they have are intractable or permanent such as cancer. Some of them are non-chronic. They suffer from diseases because of several reasons. One of these reasons is that they do not care about their personal hygiene. Where that, some of them are not taking a shower for a long period of time, maybe it reaches to consecutive three months. But, what about the reasons which made them do not bathe? There are many reasons; one of them is that they do not have houses that mean there is no place to take a shower for them. In addition, lack of awareness is one of core reasons. Where that there is no one tells them that ablution is very significant for their health. So, most of them do not have knowledge about the importance ablution for their health. This is because the majority of them do not have families and friends which mean they do not have anyone help to know the health ailments which maybe happened because of lack of ablution. Also, most of governments in the world do not contact with them and show them the risk of not washing.

Poor nutrition is one of disease causes. Homeless people usually do not eat for a long time. Also, when they eat, they eat leftovers. For example, as we see them often, they collect their food from the trash which means they feed on unhealthy food. Consequently, it is normal that they will have healthy problems. On the other hand, most the hospitals in the world are not free and are not cheap. So, homeless people face difficulties to treat themselves. As we know that homeless people do not have money to have food which means they do not have the financial capacity to pay to the hospital in order to manage to be treated.

\section{The issues of homeless people}

Homeless people have a lot of issues which they have to deal with. Poverty is one of these issues. Homeless people have a lot of issues which they should deal with. Poverty is one of these issues. They do not have the money which ensures to them accommodation and food. Where that most of them do not have jobs and they find it difficult to get jobs. This goes back to that they are non-eligible to get jobs which means there are no sources of income for them.

Most institutions and companies do not accept them because of lack of education. Also, some homeless people do have the motivation for work. As mentioned previously, poverty is the core cause for homeless people. "Homelessness is rooted hard and deep in poverty. Homeless are poor people they come overwhelmingly from poor families" [22]. So, according to Liebow [22] it shows us that poverty is the only major 
Page 3 of 4

problem for homelessness. This issue is very important, so it necessary to solve it. There are many solutions for this issue. One of them is supporting charities. The charities are the nearest to homeless people for ease their suffering.

In America, according to the statistic from the Nation Indicate that the number of people who are living in extreme poverty (less than $\$ 11,510$ for a family of four) is 20.4 million, 1 in 15 Americans, including more than 15 million women and children [23]. They do not have the money which ensures to them accommodation and food. Where that most of them do not have jobs and they find it difficult to get jobs. This goes back to that they are non-eligible to get jobs which means there are no sources of income for them. Most institutions and companies do not accept them because of lack of education. Also, some homeless people do have the motivation for work. As mentioned previously, poverty is the core cause for homeless people. Roleff says that "homelessness is rooted hard and deep in poverty. Homeless are poor people and they come overwhelming from poor families". So, according to what Roleff says, it shows us that poverty is the only major problem for homelessness. This issue is very important, so it is necessary to solve it. There are many solutions for this issue. One of them is supporting charities. The charities are the nearest to homeless people to ease their suffering. Where that supporting charities will improve homeless people's living for the better. As soon as the charitable organizations receive funds from government or other people, the situation of homeless people will rise for the better. For example, when we donate to the charitable organizations, they will spend our donation to build houses for homeless people. Also, facilitating the access to education is of best solution for homelessness. Through, grant scholarships to continue their education or make the education free for low income. Where that education is makes homeless people eligible to get jobs. Then, they will be able to depend on themselves.

In addition, loneliness considered from the issues which homeless people suffer. The feelings of loneliness experienced by the homeless can have very detrimental effects both on their spiritual, physical and emotional health. Loneliness has been linked to such maladies as anxiety, hostility, depression, poor self-concept, alcoholism, and psychosomatic illnesses [24]. All of these reactions due to loneliness, therefore, it must be solved. This problem will be resolved by finding organizations to take care of homeless people and to be a meeting place. So, they will get to know each other, and then they will not feel lonely. Also, there is a method for many homeless people to overcome feelings of intense loneliness is to acquire pets as Kennedy says.

\section{Discussion and Conclusion}

In conclusion, this phenomenon is like most social phenomena, but it is sensitive to all social levels to the community. Thus, it requires many of the concerted efforts of both researchers meetings and economists, in addition to the efforts of civil society. Homelessness is a serious problem and phenomenon in the same time that impacts thousands of people each year in many countries. It is a problem that also the governments and societies are committed to tackling more effectively each year. There should be more homeless refuges and faculties for those in need, as homeless people are humans just like the rest of us. People should definitely sympathize to homeless people, because with the right charities, institution, support and help, homelessness could be overcome, and homeless people will be able to make a change in their lives. There are plenty of ways to improve the fate of homeless people and homelessness needs a lot of work to be solved. It is not so easily solved as some might expect. But, also it is not impossible. Therefore, it is important not to underestimate their status or make it a regular sight, and to ensure that access to it must be recruiting international community, which can and must decide how to treat their status.

\section{Conflicts of Interest}

There are no conflicts.

\section{References}

1. Rew L, Grady M, Dunman K (2008) Differences in adolescents perceived health status and sexual behavior by duration of homelessness and gender. J Adolesc Health 42: 11.

2. Robertson MJ, Toro PA (1993) Homeless youth: Research, intervention, and policy practical lessons: The 1998 national symposium on homelessness research. Department of Housing and Urban Development, Washington DC.

3. Tyler KA, Whitbeck LB, Chen XJ, Johnson K (2007) Sexual health of homeless youth: Prevalence and correlates of sexually transmissible infections. Sexual Health 4: 57.

4. Whitbeck LB, Hoyt DR, Ackley KA (1997) Abusive family backgrounds and later victimization among runaway and homeless adolescents. J Res Adolesc 7: 375-392.

5. Reaching Homeless Youths and Young Adults in Boston (2006) Emmanuel Gospel Center.

6. Nunez R (1995) An American family myth: Every child at risk. Homes for the Homeless, New York.

7. Slavin P (2001) Life on the run, life on the streets. Children's Voice Magazine.

8. Desjardins L (2015) A glance at the participation of adult workers in formal, job- related training activities or education. Statistics Canada.

9. Neale J (2001) Homelessness among problem drug users: A double jeopardy explored. Int J Drug Policy 12: 353-369.

10. Greene JM, Ennett ST, Ringwalt CL (1997) Substance use among runaway and homeless youth in three national samples. Am J Public Health 87: 229-235.

11. Smollar J (1999) Homeless youth in the United States: Description and developmental issues. New Directions for Child \& Adolescent Development 85: 47-58.

12. Zerger S, Strehlow AJ, Gundlapalli AV (2008) Homeless young adults and behavioral health. Am Behav Sci 51: 854-841.

13. Salomonsen-Sautel S, Van Leeuwen JM, Gilroy C, Boyle S, Malberg D, et al. (2008) Correlates of substance use among homeless youths in eight cities. Am J Addict 17: 224-234.

14. Schwartz M, Sorensen HK, Ammerman S, Bard E (2008) Exploring the relationship between homelessness and delinquency: A snapshot of a group of homeless youth in San Jose. Child Adolesc Soc Work 25: 255-269.

15. Coumans M, Spreen M (2003) Drug use and the role of homelessness in the process of marginalization. Substance Use and Misuse 38: 311-338.

16. Neale J (2001) Homelessness among problem drug users: A double jeopardy explores. Int J Drug Policy 12: 353-369.

17. Education of Homeless Children and Youth (2009) The National Coalition for the Homeless.

18. Les BW, Xiaojin C, Dan RH, Kimberly AT, Kurt DJ, et al. (2004) Mental disorder, subsistence strategies, and victimization among gay, lesbian, and bisexual homeless and runaway adolescents. J Sex Res 41: 329-342.

19. Thompson S, Pollio D, Constantine J, Reid D, Nebbitt V (2002) Shortterm outcomes for youth receiving runaway and homeless shelter services. Research on Social Work Practice 12: 589-603.

20. MacLean M, Embry L, Cauc A (1999) Homeless adolescent's paths to separation from family: Comparison of family characteristics, 
Citation: $\quad$ Alowaimer O (2018) Causes, Effects and Issues of Homeless People. J Socialomics 7: 223. doi:10.41 72/2167-0358.1000223

Page 4 of 4

psychological adjustment, and victimization. Journal of Community Psychology 27: 179-187.

21. Theresa K (2006) Loneliness, homelessness a toxic mix. Street Roots Newspaper.

22. Liebow E (1994) Tell them who I am: The lives of homeless women. J Am Plann Assoc 23: 203-204.
23. Violence, Harassment and Bullying and Homelessness (2015) Australian Human Rights Commission.

24. David B, Bruno L (1996) Homeless and poverty. The Homeless Opposing Viewpoints. 